\title{
PENGARUH CELEBRITY ENDORSEMENTTERHADAP PURCHASE INTENTION DENGANBRAND IMAGE SEBAGAI VARIABEL INTERVENING (STUDI KASUS IKLAN PRODUK PERAWATAN KECANTIKAN POND'S)
}

\author{
Finna Anastasia Wijaya ${ }^{1}$, Sugiono Sugiharto ${ }^{2}$ \\ ${ }^{1}$ Alumnus Program Manajemen Pemasaran, Universitas Kristen Petra \\ Jl. Siwalankerto 121-131, Surabaya \\ E-mail: finnawijayaa@gmail.com \\ ${ }^{2}$ Program Manajemen Pemasaran, Universitas Kristen Petra \\ Jl. Siwalankerto 121-131, Surabaya \\ E-mail: sugiono@petra.ac.id
}

\begin{abstract}
Abstrak: Penelitian ini bertujuan untuk menganalisa pengaruh dari Credibility, Attractiveness, dan Power terhadap Purchase Intention produk kecantikan Pond'sdengan mempertimbangkan faktor Brand Image (Sincerity, Excitement, Competence, dan Shophistication).Penelitian dilaksanakan dengan menyebarkan kuesioner kepada 100 responden yang pernah melihat iklan Pond's dalam waktu 2 bulan terakhir. Teknik analisa yang digunakan adalah teknik analisis kuantitatif dengan metode path analysis. Hasil penelitian menunjukkan bahwa variabel yang berpengaruh signifikan hanya Attractiveness, Power, Brand image dan Purchase intention.
\end{abstract}

Kata kunci: Credibility, Attractiveness, Power, Brand image, Purchase intention.

\begin{abstract}
This study aims to analyze the influence of Credibility, Attractiveness, and Power to Purchase Intention beauty products Pond'sdengan consider factors Brand Image ( Sincerity, Excitement, Competence , and Shophistication ).Penelitian conducted by distributing questionnaires to 100 respondents who had seen the ads Pond's in the last 2 months. Analysis technique used is the technique of quantitative analysis analysis. Hasil path method showed that the variables that have a significant effect only Attractiveness, Power, Brand image and Purchase intention
\end{abstract}

Keywords: Credibility, Attractiveness, Power, Brand image, Purchase intention

\section{PENDAHULUAN}

Setiap orang tentu ingin tampil cantik atau tampan sebagai sebuah tuntutan untuk menunjang sikap percaya diri dalam setiap aktivitas sehari-hari. Rasa percaya diri tersebut membuat motivasi diri juga semakin bertambah begitu pula cara bekerja dan cara berpikirnya. Penampilan merupakan hal yang perlu mendapatkan perhatian oleh semua orang terutama yang memiliki aktivitas bekerja di luar rumah.Salah satu hal yang menjadi perhatian adalah memiliki kulit yang bersih dan putih.

Beragam merek produk perawatan kulit tersedia di pasar di Indonesia. Keragaman merek tersebut menyebabkan terjadinya persaingan yang ketat dalam industri perawatan kulit, sehingga mengharuskan perusahaan berupaya keras untuk mempertahankan pangsa pasar yang telah dikuasai, bahkan apabila memungkinkan memperluas pangsa pasar tersebut. Strategi yang sangat penting untuk memenangkan persaingan yang dilakukan perusahaan, yaitu strategi pemasaran.
Ada banyak cara strategi pemasaran yang layak dipelajari, kemudian perusahaan dapat memilih salah satu alternatif cara yang dipandang sesuai dengan kondisi perusahaan. Iklan adalah salah satu pilihan yang ditempuh oleh perusahaan untuk berkomunikasi dengan publiknya. Penggunaan selebritis dalam iklan diharapkan akan mampu menarik perhatian pemirsa, sehingga iklan dapat diingat di benak pemirsa. Clemente (2002) menjelaskan bahwa celebrity endorsement merupakan penggunaan selebriti dalam iklan dengan tujuan merekomendasikan penggunaan produk yang disponsori.

Penelitian ini akan menggunakan objek produk perawatan kecantikan merek Pond's. Dalam menghadapi persaingan dengan produk perawatan kulit lainnya, Pond's menggunakan iklan untuk mempromosikan produknya dan didukung oleh selebritis sebagai endorser iklan.

Penggunaan selebritis sebagai endorser untuk mempromosikan produk Pond's dapat dikatakan masih belum maksimal, meskipun ada kesesuaian antara atribut yang dimiliki selebritis dengan produk 
Tabel 1. Top Brand Index Produk Perawatan Kulit

\begin{tabular}{|c|c|c|c|c|c|c|c|c|c|}
\hline \multicolumn{2}{|c|}{$\begin{array}{c}\text { Sabun Pembersih } \\
\text { Wajah }\end{array}$} & \multicolumn{2}{|c|}{$\begin{array}{l}\text { Pelembab } \\
\text { Wajah }\end{array}$} & \multicolumn{2}{|c|}{ Krim Pemutih } & \multicolumn{2}{|c|}{ Foundation } & \multicolumn{2}{|c|}{$\begin{array}{l}\text { Hand \& Body } \\
\text { Lotion }\end{array}$} \\
\hline Pond's & $39,4 \%$ & Pond's & $47,7 \%$ & Pond's & $51,6 \%$ & Revlon & $17,5 \%$ & Citra & $34,5 \%$ \\
\hline Biore & $23,3 \%$ & Olay & $6,6 \%$ & Ganier & $10.8 \%$ & La Tulipe & $12,0 \%$ & Marina & $15,9 \%$ \\
\hline Papaya & $5,6 \%$ & Sariayu & $5,8 \%$ & Olay & $4,6 \%$ & Wardah & $9,2 \%$ & Nivea & $5,5 \%$ \\
\hline Garnier & $5,3 \%$ & Nivea & $5,3 \%$ & The Fuk & $2,5 \%$ & Sariayu & $6,4 \%$ & Viva & $2,8 \%$ \\
\hline Nivea & $2,3 \%$ & Viva & $4,3 \%$ & Sariayu & $1,6 \%$ & Pond's & $6,0 \%$ & Pond's & $2,2 \%$ \\
\hline
\end{tabular}

Sumber: http://www.topbrand-award.com

Pond's. Hal ini bisa dilihat dari Top Brand Index untuk produk perawatan kulit yang pada kategori tertentu menempatkan Pond'ssebagai top brand, namun pada kategori lainnya merek Pond's tidak menempati posisi pertama.

Berdasarkan tabel diatas menunjukkan merek Pond's hanya menduduki posisi pertama untuk kategori produk sabun pembersih wajah, pelembab wajah, dan krim pemutih.Sedangkan untuk kategori foundation serta hand \& body lation berada di posisi keempat.Hal inilah yang menarik bagi penulis karena penggunaan celebrity endorsement dalam iklan Pond's belum sepenuhnya menjaga konsistensi loyalitas konsumen Pond's.

Dilihat dari fenomena yang terjadi di atas, maka penulis mengambil rumusan masalah sebagai berikut:

1. Apakah ada pengaruh credibility terhadap brand image?

2. Apakah ada pengaruh attractiveness terhadap brand image?

3. Apakah ada pengaruh power terhadap brand image?

4. Apakah ada pengaruh brand image terhadap purchase intention?

\section{TINJAUAN PUSTAKA}

\section{Celebrity Endorsement}

Selebritis memiliki pengertian sebagai individu yang telah mencapai tingkat ketenaran yang membuatnya dikenal di masyarakat. Perkembangan budaya yang ada menyebabkan masyarakat memiliki rasa ingin tahu tentang kepribadian selebriti (Young dan Pinsky, 2006).Sebagai seseorang yang dikenal di masyarakat, maka selebritis sering digunakan untuk mendukung suatu iklan. Diperkirakan bahwa sekitar satu dari enam iklan di dunia menggunakan figur selebritis.

Clemente (2002) menjelaskan bahwa celebrity endorsement merupakan penggunaan selebriti dalam iklan dengan tujuan merekomendasikan penggunaan produk yang disponsori. Menurut Choi dan Rifon (2007) selebritis dalam iklan adalah individu yang merupakan ikon atau simbol yang populer di masyarakat dan mentransfer makna simbolisnya untuk produk yang diiklankan.

Shimp dan Andrews (2013) menyebutkan ada beberapa atribut celebrity endorsement, yaitu:

1. Kredibilitas (credibility), mengacu pada kecenderungan untuk percaya atau mempercayai endorser. Jika sebuah sumber informasi, seperti endorser dianggap kredibel. Ada dua dimensi penting dalam atribut kredibel yaitu:

a. Keahlian (expertise)

Keahlian mengacu pada pengetahuan, pengalaman, atau keterampilan yang dimiliki oleh endorser.

b. Trustworthiness (kepercayaan)

Kepercayaan mengacu pada kejujuran yang dirasakan, integritas, endorser merupakan orang yang dapat dipercaya oleh khalayak

2. Attractiveness (daya tarik) terdiri dari tiga dimensi yang terkait kesamaan, keakraban, dan disukai. Sumber dianggap menarik untuk penerima jika ada kesamaan atau keakraban dengan sumber, dan jika penerima menyukai sumber terlepas dari apakah keduanya memiliki kesamaan atau tidak dalam hal apapun.Daya tarik tidak hanya fisik, tapi juga meliputi sejumlah karakteristik yang menjadi kelebihan endorser, seperti keterampilan intelektual, sifat kepribadian, karakteristik gaya hidup, kecakapan dan sebagainya.

3. Power (kekuatan) merupakankharisma yang dipancarkan oleh narasumber sehingga dapat mempengaruhi pemikiran, sikap, atau tingkah laku konsumen karena pernyataan atau pesan endorser tersebut.

\section{Brand Image}

Brand image merupakan asosiasi yang aktif di memori ketika seseorang berpikir tentang merek tertentu(Shimp, 2010). Brand image dapat diartikan sebagai persepsi tentang merek yang tercermin oleh asosiasi merek diadakan di memori konsumen.Brand image terdiri dari pengetahuan dan keyakinan konsumen tentang merek.Konsumen yang memiliki 
persepsi positif terhadap suatu merek berarti merek tersebut memiliki pesan yang kuat dibandingkan dengan pesan merek pesaing (Lee, et.al, 2011).

Pengertian lain mengenai brand image adalah seperangkat keyakinan tentang merek tertentu (Meenaghan, 1995). Sedangkan pengertian brand image menurut Rangkuti (2009) adalah sekumpulan asosiasi merek yang terbentuk di benak konsumen. Konsumen yang terbiasa menggunakan merek tertentu cenderung memiliki konsistensi terhadap merek tersebut.

Shimp (2010) menyebutkan beberapa dimensi dalam brand image terdiri dari:

1. Sincerity, dimensi ini meliputi merek yang dianggap sebagai jujur dan apa adanya.

2. Excitement merek dianggap sebagai berani, bersemangat, imajinatif, dan up to date. Competence yaitu merek dianggap handal, cerdas, dan sukses.

3. Sophistication yaitu merek yang dianggap berkelas dan mewah

\section{Purchase Intention}

Purchase intention dapat diartikan sebagai kemungkinan bahwa konsumen akan melakukan pembelian produk tertentu. Selain itu, dapat diartikan juga sebagai rencana dari konsumen untuk melakukan upaya dalam membeli. Kesediaan pelanggan untuk membeli memiliki probabilitas yang lebih tinggi, meskipun pelanggan belum tentu benar-benar membelinya.Niat beli ditentukan oleh manfaat dan nilai yang dirasakan oleh konsumen (Wang dan Tsai, 2014)

Niat beli juga dapat diartikan sebagai konsumen lebih memilih untuk membeli produk atau layanan karena merasa bahwa membutuhkan produk atau jasa tersebut (Madahi dan Sukati, 2012). Jaafar dan Laalp (2013) menjelaskan bahwa niat beli adalah penggunaan alat yang efektif dalam memprediksi proses pembelian. Setelah konsumen memutuskan untuk membeli produk di toko tertentu didasarkan pada dorongan karena niat yang dimilikinya.

Menurut Rahman et.al (2012), purchase intention dapat diukur menggunakan indikator sebagai berikut:

1. Kesediaan konsumen yang akan melakukan pembelian

2. Keinginan konsumen untuk melakukan pembelian di masa depan

3. Keinginan konsumen untuk melakukan pembelian ulang

Menurut Shah et.al. (2012), purchase intention ditentukan juga oleh sikap konsumen terhadap merek dari barang yang hendak dibeli (atittude towards brands).Dalam memilih suatu merek, konsumen melakukan evaluasi dengan membandingkan beberapa merek yang memenuhi kriteria dan dirasa dapat memenuhi kebutuhan dan keinginan konsumen.

\section{Kerangka Konseptual}

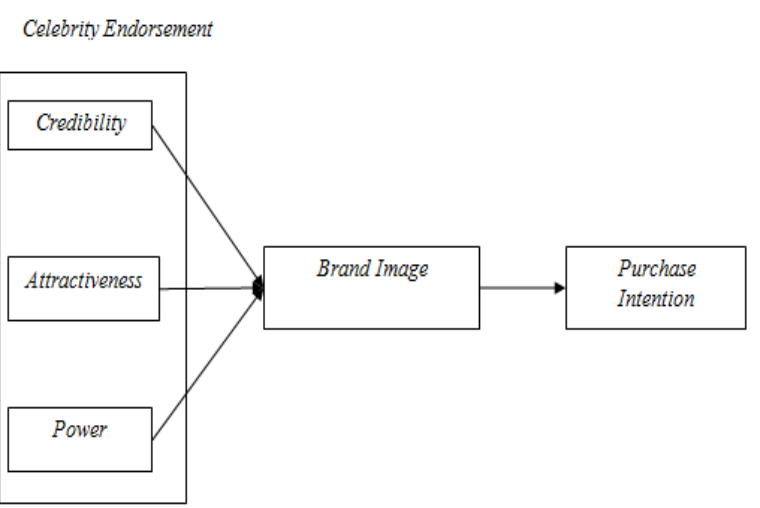

Gambar 1. Kerangka konseptual

\section{Hipotesis}

Hipotesis 1: Didugacredibility berpengaruh signifikan terhadap brand image

Hipotesis 2: Didugaattractiveness berpengaruh signifikan terhadap brand image

Hipotesis 3: Didugapower berpengaruh signifikan terhadap brand image

Hipotesis 4: Didugabrand image berpengaruh signifikan terhadap purchase intention

\section{METODE PENELITIAN}

\section{Populasi dan Sampel}

Populasi dapat diartikan sebagai wilayah generalisasi yang terdiri dari obyek atau subyek yang mempunyai kualitas dan karakteristik tertentu yang ditetapkan oleh peneliti untuk dipelajari dan kemudian ditarik kesimpulannya (Sugiyono, 2012).Populasi dalam penelitian ini adalah masyarakat Surabaya yang melihat iklan Pond's. Sedangkan, sampel merupakan bagian tertentu yang dipilih dari populasi atau tiap bagian dari populasi, yang dipilih berdasarkan apakah itu representatif atau tidak (Silalahi, 2009).

Teknik pengambilan sampel dalam penelitian ini adalah nonprobability sampling, yaitu teknik pengambilan sampel yang tidak memberi peluang atau kesempatan yang sama bagi setiap unsur atau anggota populasi untuk dipilih menjadi sampel. Jenis nonprobability sampling yang digunakan adalah purpo- 
sive sampling dengan menggunakan karakteristikkarakteristik sebagai berikut:

1. Berjenis kelamin laki-laki atau perempuan dengan usia minimal 17 tahun

2. Pernah menonton iklan Pond's minimal dalam rentang waktu 2 bulan terakhir.

\section{Definisi Operasional Variabel}

Untuk memberi batasan pengukuran agar tidak terjadi kesalahan dalam hal menafsirkan, variabel yang dianalisis perlu didefinisikan. Definisi operasional yang akan dianalisis sebagai berikut:

- Variabel Eksogen

Credibility $\left(\mathrm{X}_{1}\right)$

1. Berniat melakukan pembelian produk dikarenakan ketertarikan akan bintang iklannya

2. Berniat melakukan pembelian dikarenakan percaya produk dapat menambah kecantikan seperti bintang iklannya

3. Berniat melakukan pembelian produk dikarenakan yakin dengan janji-janji yang disampaikan oleh bintang iklannya

Attractiveness $\left(\mathrm{X}_{2}\right)$

1. Berniat melakukan pembelian produk dikarenakan memiliki kesamaan permasalahan kulit dengan bintang iklannya

2. Berniat melakukan pembelian produk dikarenakan ingin mengikuti gaya hidup bintang iklannya

3. Berniat melakukan pembelian produk dikarenakan bintang iklan yang digunakan sedang trend saat ini

Power $\left(\mathrm{X}_{3}\right)$

1. Berniat melakukan pembelian produk dikarenakan terpengaruh oleh kata-kata bintang iklannya

2. Berniat melakukan pembelian produk dikarenakan terpengaruh oleh kharisma yang dipancarkan oleh bintang iklannya

3. Berniat melakukan pembelian produk dikarenakan terpengaruh oleh kondisi fisik bintang iklannya

- Variabel Intervening

Brand Image $\left(\mathrm{Y}_{1}\right)$

Sincerity

1. Produk yang diiklankan sama dengan yang dijual di pasaran.

2. Manfaat produk diiklankan sebagaimana adanya.

3. Tampilan bintang iklan produk mencerminkan kualitas produk.

\section{Excitement}

1. Iklan produk memberikan inspirasi tersendiri

2. Iklan produk selalu memberikan informasi produk yang up to date.

3. Iklan produk unik dan berbeda dari produk sejenis lainnya.

Competence

1. Merek produk merupakan merek yang dapat diandalkan

2. Merek produk merupakan merek yang sukses di pasaran

3. Merek produk merupakan merek yang menjanjikan

Sophistication

1. Merek produk merupakan merek yang berkelas mewah

2. Merek produk merupakan merek yang memiliki nilai prestisius

3. Merek produk merupakan merek yang terkenal

- Variabel Endogen

Purchase Intention $\left(\mathrm{Y}_{2}\right)$

1. Kesediaan konsumen yang akan melakukan pembelian

2. Keinginan konsumen untuk melakukan pembelian di masa yang akan datang

3. Keinginan konsumen membeli produk karena mereknya yang terkenal

\section{Teknik Analisa Data}

Alat ukur yang digunakan adalah structural equation modelling (SEM) dengan program PLS (Partial Least Square).

a. Dilakukan tahap evaluasi reliabilitas yang terbagi menjadi dua tahap, yaitu evaluasi indicator reliability, danevaluasi internal consistency reliability. Evaluasi reliabilitas ini dilakukan untuk melihat apakah data yang digunakan didalam penelitian ini konsisten atau tidak, karena hal ini dapat berpengaruh besar terhadap output data yang akan diuji selanjutnya.

b. Kemudian dilakukan evaluasi validitas data dengan menggunakan convergent validity dan discriminant validity, dimana evaluasi ini bertujuan untuk melihat apakah variabel yang digunakan didalam penelitian ini akurat dalam melakukan pengolahan data.

c. Dilakukan uji path coefficient dan coefficient of determination.

d. Digunakan metode bootstrapping untuk mencari nilai $t$-statistics yang penggunaannya adalah untuk pengujian hipotesis. 


\section{ANALISA DAN PEMBAHASAN}

\section{Evaluation Measurement Model (Outer Model)}

Uji Reliabilitas

Pengukuran reliabilitas, dapat dilakukan dengan pengukuran internal consistency reliability untuk mengukur seberapa konsisten indikator tiap-tiap variabel yang ada.Composite Reliability untuk mengukur internal consistency reliability sebagai pengganti Cronbach's Alpha pada penelitian modern. Nilai composite reliability harus lebih dari 0,6 agar sebuah variabel dapat dikatakan reliable.

Tabel 2. Internal Consistency Reliability

\begin{tabular}{lcc}
\hline \multicolumn{1}{c}{ Variabel } & Composite Reliability & Keterangan \\
\hline Credibility & 0,912808 & Reliable \\
Attractiveness & 0,926249 & Reliable \\
Power & 0,917662 & Reliable \\
Brand Image & 0,965515 & Reliable \\
Purchase Intention & 0,942744 & Reliable \\
\hline
\end{tabular}

Tabel 2 Dapat dilihat bahwa keseluruhan variabel memiliki nilai composite reliability diatas 0,6, sehingga dapat disimpulkan bahwa keseluruhan variabel memiliki level internal consistency reliability yang tinggi.

\section{Uji Validitas}

Menurut Bagozzi \& Yi (1988) convergent validity dilihat berdasarkan nilai average variance extracted (AVE) yang didapat melalui partial least square regression. Nilai AVE harus lebih besar dari 0.50 agar dapat dikatakan valid.

Tabel 3. Convergent Validity

\begin{tabular}{lcc}
\hline \multicolumn{1}{c}{ Variabel } & AVE & Keterangan \\
\hline Credibility & 0,777908 & Valid \\
Attractiveness & 0,807213 & Valid \\
Power & 0,787987 & Valid \\
Brand Image & 0,700250 & Valid \\
Purchase Intention & 0,767141 & Valid \\
\hline
\end{tabular}

Tabel 3 menunjukkan bahwa keseluruhan variabel yang digunakan pada penelitian ini memiliki convergent validity yang layak. Dengan memastikan convergent validity, maka dapat dilanjutkan untuk pemeriksaan validitas tahap selanjutnya.

\section{Evaluasi Structural Model (Inner Model)}

Uji R-Square

Coefficient determination $\left(\mathrm{R}^{2}\right)$ digunakan untuk mengukur seberapa banyak variabel endogen dipengaruhi oleh variabel lainnya. Didalam marketing research, nilai $\mathrm{R}^{2}$ diatas 0,75 keatas dikategorikan substansial, 0,50-0,75 artinya sedang, dan 0,25-0,50 artinya lemah.

Tabel 4 menunjukkan angka 0,817. Artinya sebesar $81,7 \%$ brand image dipengaruhi oleh celebrity endorsement yang terdiri dari credibility, attractiveness, power sedangkan sisanya sebesar $18,3 \%$ dipengaruhi oleh variabel lain diluar penelitian.

Tabel 4. Hasil $R$-square

\begin{tabular}{lc}
\hline \multicolumn{1}{c}{ Variabel } & Coefficient of Determination $\left(\mathrm{R}^{2}\right)$ \\
\hline Purchase Intention & 0,887 \\
Brand Image & 0,817 \\
Power & \\
Attractiveness & \\
\hline Credibility & \\
\hline
\end{tabular}

Selanjutnya variabel brand image mempengaruhi purchase intention sebesarsebesar 0,887 dimana $88,7 \%$ terbentuknya purchase intention dijelaskan oleh variabel brand image sementara sisanya 11,3\% dipengaruhi oleh variabel lain yang tidak ikut diteliti dalam penelitian ini.

\section{Uji Hipotesa dan T-statistik}

Nilai T-statistics diperoleh dari prosedur bootstrapping, dimana nilai ini digunakan untuk menarik kesimpulan pada uji hipotesis. Nilai T-statistics dengan level signifikansi 5\% menjelaskan bahwa inner model akan signifikan jika nilai T-statistics lebih besar dari 1,96 .

Tabel 5. Uji Hipotesis

\begin{tabular}{lccccc}
\hline & $\begin{array}{c}\text { Original } \\
\text { Sample } \\
(\mathrm{O})\end{array}$ & $\begin{array}{c}\text { Sample } \\
\text { Mean } \\
(\mathrm{M})\end{array}$ & $\begin{array}{c}\text { Standard } \\
\text { Deviation } \\
(\text { STDEV) }\end{array}$ & $\begin{array}{c}\text { Standard } \\
\text { Error }\end{array}$ & $\begin{array}{l}\text { T Statistics } \\
(\text { O/STERR) }\end{array}$ \\
\hline Credibility $\rightarrow$ Brand Image & $0,1796810,179935$ & 0,094945 & 0,094945 & 1,892473 \\
Attractiveness $\rightarrow$ Brand image & $0,3227050,322525$ & 0,092734 & 0,092734 & 3,479910 \\
Power $\rightarrow$ Brand Image & $0,4853200,486498$ & 0,078577 & 0,078577 & 6,176355 \\
Brand Image $\rightarrow$ Purchase & $0,9418610,942841$ & 0,011520 & 0,011520 & 81,756488 \\
Intention & & & & & \\
\hline
\end{tabular}

Dari Tabel 5. T-statistics pada pengaruh credibility terhadap brand image menunjukkan angka 1,892473 , artinya credibility tidak berpengaruh signifikan terhadap brand image.

T-statistics pada pengaruh attractiveness terhadap brand image menunjukkan angka 3,479910, artinya attractiveness berpengaruh signifikan terhadap brand image.

T-statistics pada pengaruh powert erhadap brand image menunjukkan angka 6,176355, artinya power berpengaruh signifikan terhadap brand image. Sedangkan T-statistics pada pengaruh brand image 
terhadap purchase intention menunjukkan angka 81,756488 , artinya brand image berpengaruh signifikan terhadap purchase intention.

Berikut adalah hasil penarikan kesimpulan dari uji hipotesis.

\section{Pembahasan}

\section{Credibility terhadap Brand Image}

Menurut Okonkwo (2007) dukungan selebritis dalam iklan memiliki persyaratan bahwa kepribadian dan status selebritis seperti kesuksesan, kaya, berpengaruh harus memiliki kaitan secara langsung dengan merek. Atribut selebritis seperti kredibilitas endorser akan berpengaruh terhadap citra produk. Kredibilitas endorser dalam iklan akan mampu meningkatkan citra positif produk yang pada akhirnya akan meningkatkan ekuitas merek.

Tetapi hasil penelitian menunjukkan bahwa credibility tidak memberi pengaruh signifikan terhadap brand image. Hal ini dikarenakan nilai $\mathrm{T}$ statistics yang didapatkan sebesar 1,892473 di mana nilai ini kurang dari 1,96. Hal ini dapat terjadi dikarenakan responden menganggap kredibilitas seorang selebriti yang terdiri dari keahlian bintang iklan Pond's, ketertarikan bintang iklan Pond's baik dari kecantikan dan janji yang diucapkan oleh selebriti tersebut tidak selalu dapat membangun suatu brand image Pond's yang positif. Responden menganggap hal ini masih kurang dan belum tepat sasaran.

\section{Attractiveness terhadap Brand Image}

Menurut Rini dan Astuti (2012) ada dua hal penting dalam penggunaan selebriti jika dihubungkan dengan daya tarik (attractiveness), pertama adalah tingkat disukai audience (likebility) dan tingkat kesamaan dengan personality yang diinginkan pengguna produk (similarity), dimana keduanya tidak dapat dipisahkan.

Berdasarkan hasil penelitian yang telah diperoleh diketahui bahwa dalam analisis path coefficient hubungan dari attractiveness menuju brand image memiliki nilai sebesar 0,323 dan hasil uji hipotesis Tstatistik >1,96 adalah sebesar 3,479910. Dapat dikatakan terdapat pengaruh positif dari variabel attractiveness menuju brand imagedan juga memiliki pengaruh yang signifikan.

Hasil penelitian ini menunjukkan bahwa responden beranggapan selebritis yang digunakan oleh Pond's memiliki kesamaan dengan produk yang diiklankan, contohnya adalah bintang iklan Pond's memiliki permasalahan kulit yang sama dengan masalah yang dihadapi oleh konsumen.Dengan begini, hal ini dapat membangun daya tarik sendiri di hati konsumen dan selebriti pendukung Pond's tersebut dapat mencerminkan personality dari merek yang ingin dibangunnya melalui iklan.

\section{Power terhadap Brand Image}

Hasil penelitian menunjukkan ada pengaruh power terhadap brand image, dilihat dari hasil path coefficient yang menunjukkan angka 0,486 dan memiiki pengaruh yang signifikan dikarenakan nilai T-statistics yang didapatkan sebesar 6,176355 di mana nilai ini lebih besar dari 1,96.Hubungan dari power ke brand image juga merupakan pengaruh yang memiliki angka paling besar dibandingkan dengan kedua variable sebelumnya yaitu credibility dan attractiveness.

Menurut Rini dan Astuti(2012) power berhubungan dengan kekuatan yang dimiliki selebriti untuk memerintahkan target audience untuk membeli. Power yang dimiliki selebritis dapat membentuk citra produk sesuai dengan karakter dari selebritis.

Di dalam hasil penelitian ini responden setuju bahwa power yang berasal dari dalam seorang selebriti pendukung Pond's dapat mempengaruhi brand image Pond's itu sendiri. Kharisma seorang artis pendukung Pond's dapat dikatakan telah membangun sebuah brand image Pond's yang sesuai dengan karakter dan pembawaan dari dalam diri artis tersebut.

\section{Brand Image terhadap Purchase Intention}

Hasil penelitian menunjukkan hipotesis keempat dalam penelitian telah terbukti yang berarti ada pengaruh brand image terhadap purchase intention. Berdasarkan nilai T-statistics yang di atas 1,96 sebesar 81,756488 dan hasil path coefficient yang menunjukkan angka 0,942 artinya pengaruh brand image terhadap purchase intention adalah positif dan signifikan (kuat).

Hasil penelitian ini sesuai dengan penelitian yang dilakukan oleh Khan et.al(2015) yang menunjukkan bahwa brand image berdampak positif terhadap niat pembelian. Oleh karena itu, pemasar harus mengembangkan program komunikasi pemasaran yang efektif yang menciptakan citra merek untuk memotivasi pelanggan agar memiliki niat beli.

Terlihat juga dari jawaban responden yang setuju akan pengaruh suatu brand image Pond's yang positif dalam mempengaruhi niat pembelian. Hal ini dikarenakan adanya trust terhadap suatu merek yang memiliki image baik dan tinggi di pasar. Dengan 
adanya image Pond's yang baik dan tinggi di pasar, responden tidak akan segan maupun ragu-ragu untuk melakukan pembelian di masa yang akan datang.

\section{KESIMPULAN DAN SARAN}

\section{Kesimpulan}

Variabel celebrity endorsement yang terdiri dari attractiveness dan power secara statistik memiliki pengaruh signifikan terhadap brand image namun, salah satu dimensi credibility tidak menunjukkan pengaruh yang signifikan. Hal ini menunjukkan bahwa pengaruh selebriti pendukung Pond's yang memiliki keahlian, kepercayaan, daya tarik memukau dan kharisma yang kuat dalam mempengaruhi audience dapat membangun asosiasi merek yang positif.

Keberadaan brand image dapat digunakan oleh pemasar untuk mendorong konsumen agar memiliki keinginan untuk membeli. Niat pembelian yang timbul dari dalam diri konsumen identik dengan brand image yang positif.

\section{Saran}

1. Penulis menyarankan kepada Pond's untuk tetap mempertahankan penggunaan selebriti pendukung dalam iklan-iklan Pond's. Namun, hendaklah selebriti yang digunakan memiliki prestasi yang baik dan tidak terlibat dalam tindakan kriminal.

2. Penulis menyarankan untuk penelitian ke depannya untuk melakukan penambahan informasi berupa penambahan indikator atau dimensi suatu variabel.

\section{DAFTAR REFERENSI}

Bagozzi, R. P., \& Yi, Y. (1988). On the evaluation of structural equation models.Journal of the Academy of Marketing Science. 20(4), 30-47.

Choi, Sejung, M., Rifon, Nora, J. (2007). Who is the celebrity in advertising? understanding dimensions of celebrity images. The Journal of popular culture, 40(2), 1-21.

Clemente, Mark N. (2002). The marketing glossary: Key terms, concepts and applications. New Jersey: Clemente Communication Group.

Jaafar, S.N., Laalp, Pan, E. (2013). Consumers perceptions, attitudes and purchase intention towards private label food products in malaysia. Asian Journal of Business and Management Sciences, 2(8), 73-90.

Khan, Nasreen., Rahmani, Syed, H.R., Hoe, Hong, Y., Chen, Tan, B. (2015). Causal relationships among dimensions of consumer-based brand equity and purchase intention: fashion indus- try. International Journal of Business and Management, 10(1), 1-10.

Lee, Hsiang-Ming., Ching-Chi Lee., Cou-Chen Wu, (2011), Brand image strategy affects brand equity after M \& A. European Journal of Marketing, 45(7/8), 1091-1111.

Madahi, Abdolrazagh, Sukati, Inda. (2012). The effect of external factors on purchase intention amongst young generation in Malaysia. International Business Research, 5(8), 1-7.

Meenaghan, Tony. (1995). The role of advertising in brand image development, Journal of Product \& Brand Management, 4(4), 23-34.

Okonkwo, Uche. (2007). Luxury fashion branding: Trends, tactics, teknik. London: Palgrave Macmillan.

Rahman, M. S., Haque, M., \& Khan, A. H. (2012). A conceptual study on consumers puchase intention of broadband services: service quality and experience economy perspective. International Journal Of Business And Management, 7(18), 115-129.

Rangkuti, Freddy. (2009). Strategi promosi yang kreatif dan analisis kasus integrated marketing communication. Jakarta: PT. Gramedia Pustaka Utama

Rini. E.S., Astuti. D.W. (2012). Pengaruh Agnes Monica sebagai celebrity endorser terhadap pembentukan brand image honda vario. Jurnal Bisnis dan Manajemen, 6(1), 1-12.

Shah, S., Aziz, J., Jaffari, A. R., Waris, S., Ejaz, W., Fatima, M., et al. (2012). The impact of brands on consumer purchase intention.Asian Journal Of Business Management, 4(2), 105-110.

Shimp, Terence. A., (2010). Integrated marketing communications in advertising and promotions. Eight edition. South-Western: Cengage Learning.

Shimp, Terence. A., Andrews, Craig, J. (2013). Advertising, promotion, and other aspects of integrated marketing communication.Ninth edition. USA: Cengage Learning.

Silalahi, Ulber. (2009). Metode penelitian sosial. Bandung: PT Refika Aditama.

Sugiyono. (2012). Statistik penelitian kuantitatif kualitatif dan $r \& d$. Bandung: Alfabeta.

Topbrand-Award. (2015). Top Brand Index Produk Perawatan Kulit. Retrieved from http://www. topbrand-award.com/

Wang, Yai, H., Tsai, Cing, F. (2014). The relationship between brand image and purchase intention: evidence from award winning mutual funds. The International Journal of Business and Finance Research, 8(2), 27-40.

Young, Mark, S., Pinsky, Drew. (2006). Narcissism and celebrity. Journal of Research in Personality, 1-9. 